\title{
A rare disease that presents with acute severe hepatitis: Kikuchi-Fujimoto disease
}

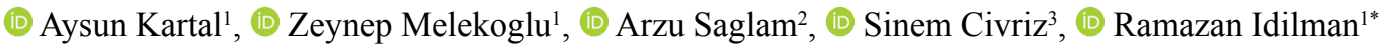 \\ ${ }^{1}$ Department of Gastroenterology, Ankara University School of Medicine, Ankara, Turkey; ${ }^{2}$ Department of Pathology, Hacettepe University Faculty of Medicine, \\ Ankara, Turkey; ${ }^{3}$ Department of Hematology, Ankara University School of Medicine, Ankara, Turkey
}

\section{Dear Editor,}

Kikuchi-Fujimoto disease (KFD), histiocytic necrotizing lymphadenitis, was first described by Japanese pathologists Kikuchi and Fujimoto. ${ }^{[1-3]} \mathrm{KFD}$ is a rare benign disease that affects young women, especially Asian women. KFD presents with painful cervical lymphadenopathy, fever episodes, fatigue, night sweat, arthralgia, odynophagia and loss of weight. ${ }^{[1-3]}$ Atypical presentation and extranodal involvement, including hepatic and splenic enlargement, exist. ${ }^{[1-5]}$ The etiology of KFD is not very well known; however, viruses and environmental factors have been potential factors in etiology. Laboratory tests are usually normal. Anemia, leukopenia, moderately increase in acute phase reactants and mild serum transaminase elevation may be seen. The clinical picture is not specific. ${ }^{[2,3]}$ A definitive diagnosis is made by excisional lymph node biopsy and a histopathological examination. ${ }^{[3-5]}$ Characteristic features include paracortical areas of necrosis, abundant karyorrhexis and mononuclear cells around the necrosis foci. ${ }^{[4]}$ No specific treatment is available. Symptomatic treatment with nonsteroidal anti-inflammatory drugs and antipyretics are recommended. KFD limits itself within 1-6 months.

\section{Case Report}

A 27-year-old young woman was admitted to the hematology clinic for fever and painful cervical lymphadenopathy one month ago. In this patient, lymphadenopathy was not regressed under amoxicillin/clavulanic acid, spiramycin and ceftriaxone treatment. Radiological imaging revealed conglomerate lymphadenopathy in the cervical region. She underwent an excisional lymph node biopsy. She was diagnosed with lymphoma and referred to our hematology clinic for treatment.

Her medical history was remarkably normal. Physical examination was normal except for cervical enlarged lymphadenopathy. Her family history was normal. There was no family history of liver disease.

Laboratory investigations included hemoglobulin of $11.7 \mathrm{~g} / \mathrm{dl}$, hematocrit of $35 \%$, white cell count of 5680 per $\mathrm{mm} 3$ and a platelet count of 491,000 per mm3. Her serum aspartate aminotransferase level was $1021 \mathrm{IU} / \mathrm{L}$ (normal range 15-35 IU/L), serum alanine aminotransferase was $850 \mathrm{IU} / \mathrm{L}$ (normal range 10-35 IU/L), gamma-glutamyl

Received: December 26, 2019; Accepted: January 07, 2020; Available online: January 20, 2020

*Ramazan Idilman is a member of the Science Academy (BA)

Corresponding author: Aysun Kartal; Ankara Universitesi Tip Fakultesi, Gastroenteroloji Bolumu, Cebeci, Ankara, Turkey

Phone: +90 312363 6213; e-mail: draysunkartal@gmail.com

(c) Copyright 2020 by Hepatology Forum - Available online at www.hepatologyforum.org

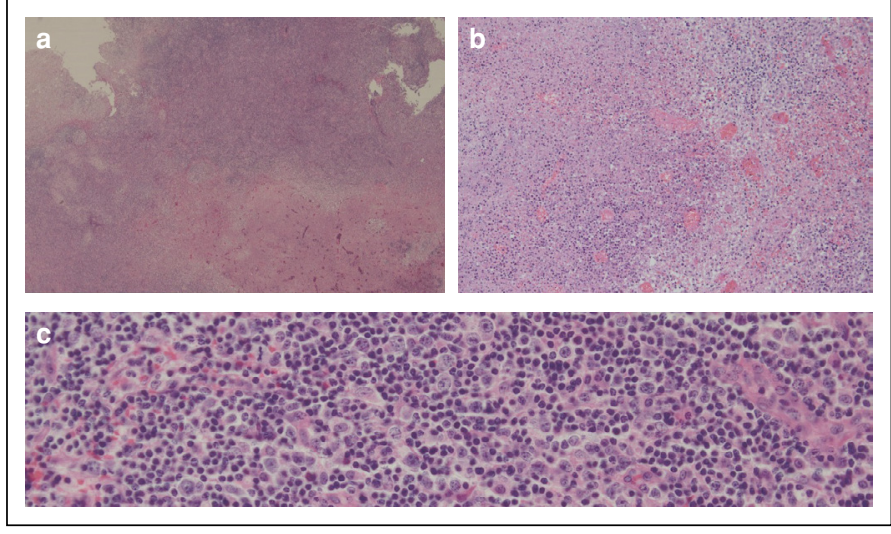

Figure 1. (a) Low power microscopy showing areas of extensive necrosis. (b) Increased vascularity, histiocytic and mononuclear cells can be seen at the border of the necrotic foci. (c) High power magnification showing reactive centroblastic and immunoblastic activated lymphoid cells.

transpeptidase was $439 \mathrm{IU} / \mathrm{L}$ (normal range 10-38 IU/L), and alkaline phosphatase was $587 \mathrm{IU} / \mathrm{L}$ (normal range 30-120 IU/L). Total bilirubin was $1.5 \mathrm{mg} / \mathrm{dL}$ (normal range $0.3-1.2 \mathrm{mg} / \mathrm{dL}$ ), and the prothrombin time was 15 seconds. The anti-nuclear antibody was found to be $1 / 100$ positive. Serum immunoglobulin $G$ was detected to be at a high level with $20.2 \mathrm{~g} / \mathrm{L}$ (normal range: $7.5-15.6 \mathrm{~g} / \mathrm{L}$ ). Serological studies for viral hepatitis were all negative. Her ceruloplasmin, copper, iron, and ferritin levels were all within the normal range. Abdominal sonography documented normal liver parenchymal appearance. The patient consulted our clinic because of severe hepatitis. We did not perform a liver biopsy because of the patient's discretion. We decided autoimmune hepatitis or drug-induced liver injury and started methylprednisolone treatment intravenously, at a dose of $1 \mathrm{mg} / \mathrm{kg} / \mathrm{day}$. At the end of the 7th day, her liver tests results improved, and then the steroid dose was tapered.

Lymph node biopsy was re-consulted. In her lymph node biopsy specimen, expanded interfollicular areas with multiple necrotic foci were observed. Histiocytes and immunoblastic cells were seen surrounding the necrotic foci, and eosinophilic apoptotic debris was present within the necrotic foci. Small lymphoid cells, plasma cells, centroblastic and immunoblastic cells, as well as an increase in histiocytic activity and vascularity within the interfollicular areas, were noteworthy. Immunohistochemical studies with CD2, CD3 and CD5 highlighted the interfollicular expansion of the T cell component. CD4 and CD8 showed an abundance of CD8 positive $\mathrm{T}$ lymphoid cells around the necrotic foci. A few immunoblastic cells were stained with CD30. CD20 and Pax-5 
highlighted the $\mathrm{B}$ follicles with PD1, CD10, Bcl-6 and CD23 positivity within germinal centers. CD15, ALK, CD56 were all negative. EpsteinBarr encoding region in situ hybridization study was negative. A diagnosis of KFD was rendered (Fig. 1).

The patient was discharged from the hospital. She has maintained normal liver injury tests receiving no treatment.

\section{Conclusion}

In summary, a case of KFD presenting with acute severe hepatitis is reported here. KFD is histiocytic necrotizing lymphadenitis and should be investigated in the differential diagnosis of acute severe hepatitis.

Peer-review: Externally peer-reviewed.

Author Contributions: Concept - AK, ZM, SC, AS, RI; Design - AK, RI; Supervision - AS, RI; Data Collection and/or Processing - AK, ZM; Literature Search - AK, SC, RI; Writing - AK, AS, RI; Critical Reviews - RI.

Conflict of Interest: The authors have no conflict of interest to declare.
Financial Disclosure: The authors declared that this study has received no financial support.

\section{References}

1. Dumas G1, Prendki V, Haroche J, Amoura Z, Cacoub P, Galicier L, et al. Kikuchi-Fujimoto disease: retrospective study of 91 cases and review of the literature. Medicine (Baltimore) 2014;93(24):372-382.

2. Cheng CY, Sheng WH, Lo YC, Chung CS, Chen YC, Chang SC. Clinical presentations, laboratory results and outcomes of patients with Kikuchi's disease: emphasis on the association between recurrent Kikuchi's disease and autoimmune diseases. J Microbiol Immunol Infect 2010;43(5):366-371.

3. Silva AF, Focaccia R, Oliveira AC, Sementilli A, Reis GF. Kikuchi-Fujimoto disease: an unusual association with acute renal failure. Braz J Infect Dis 2010;14(6):621-627.

4. Hutchinson CB, Wang E. Kikuchi-Fujimoto disease. Arch Pathol Lab Med 2010;134(2):289-293.

5. Rakesh PS, Reginald GA, Varghese GM, Mathew P, David T, Manipadam MY, et al. Kikuchi-Fujimoto Disease: Clinical and Laboratory Characteristics and Outcome. J Glob Infect Dis 2014;6(4):147-150. 